\title{
Role of Secondary Particle Formation in the Persistence of Silver Nanoparticles in Humic Acid Containing Water under Light Irradiation
}

\author{
Tuoya Zhang, ${ }^{\dagger, \ddagger}$ Dawei Lu, ${ }^{\dagger,}$ Lixi Zeng, ${ }^{\S}$ Y Yongguang Yin, ${ }^{\dagger}$ Yujian He, ${ }^{\ddagger}$ Qian Liu, ${ }^{*}, \dagger, \ddagger, \|_{\odot}$ \\ and Guibin Jiang
}

${ }^{\dagger}$ State Key Laboratory of Environmental Chemistry and Ecotoxicology, Research Center for Eco-Environmental Sciences, Chinese Academy of Sciences, Beijing 100085, China

${ }^{\ddagger}$ University of Chinese Academy of Sciences, Beijing 100049, China

${ }^{\S}$ School of Environment, Guangzhou Key Laboratory of Environmental Exposure and Health, and Guangdong Key Laboratory of Environmental Pollution and Health, Jinan University, Guangzhou 510632, China

"Institute of Environment and Health, Jianghan University, Wuhan 430056, China

Supporting Information

ABSTRACT: The wide use of silver nanoparticles (AgNPs) leads to the increasing release of AgNPs into the environment. Dissolved organic matter (DOM) is a key factor affecting the behaviors and fate of AgNPs in the aquatic environment. However, the mechanisms for the DOM-mediated transformations of AgNPs are still not fully understood. In this study, we investigated the persistence of AgNPs in the aquatic environment in the presence of different concentrations of humic acid (HA) over periods of time up to 14 days. The Ag species were monitored and characterized by absorption spectrometry, transmission electron microscopy (TEM), inductively coupled plasma mass spectrometry (ICP-MS), and multicollector ICPMS (MC-ICP-MS). Results showed that the long-term persistence of AgNPs in HA-containing water was determined

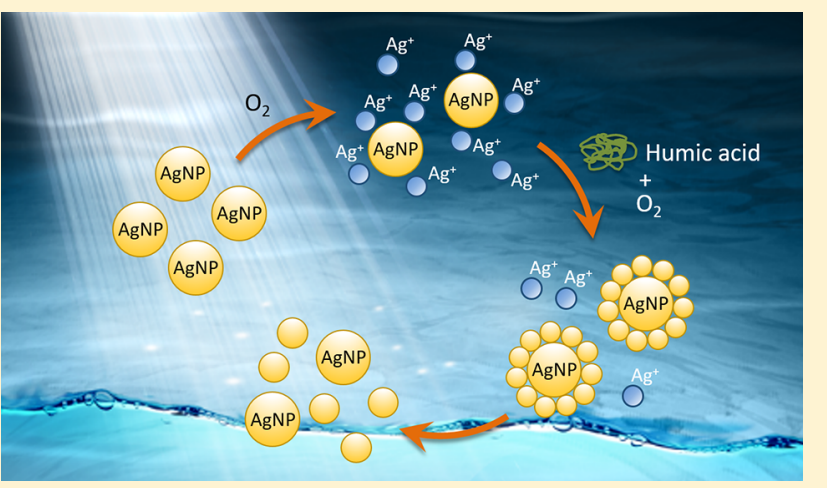
by two critical concentrations of HA. When the HA concentration exceeded a lower critical value, AgNPs could be persistent in the solution, and a large number of AgNPs were formed secondarily from the HA-induced reduction of the $\mathrm{Ag}^{+}$ions released from the primary AgNPs, causing a redistribution of the particle size. With the HA concentration above a higher critical value, AgNPs could persist in the solution without a significant change in particle size. Notably, we used Ag isotope fractionation to investigate the transformation mechanism of AgNPs. The natural isotopic analysis by MC-ICP-MS revealed that the size redistribution of AgNPs caused significant $\mathrm{Ag}$ isotope fractionation, which gave additional evidence for the proposed mechanisms. This study provides new insights into the environmental fate of engineered AgNPs and highlights the usefulness of stable isotope fractionation in environmental nanotechnology.

\section{INTRODUCTION}

In recent years, silver nanoparticles (AgNPs) have been widely applied in various physical, biological, and medicinal fields due to their excellent optical, electrical, catalytic, and especially broad-spectrum antibiotic properties. ${ }^{1-3}$ The rapidly growing production and usage amount of AgNPs leads to the inevitably increasing level of AgNPs released into the environment, ${ }^{4-6}$ which raises great concerns about their environmental toxicity and safety. A large number of studies have demonstrated that AgNPs can cause various types of toxic effects to organisms such as apoptosis, organic damage, and neurological haz$\operatorname{ards}^{7-10}$ and that the toxicity of AgNPs is mainly attributed to the release of $\mathrm{Ag}^{+}$ions. ${ }^{11-13}$
As $\mathrm{Ag}$ is a highly active element, AgNPs are easy to transform into other $\mathrm{Ag}$ species (e.g., $\mathrm{Ag}^{+}, \mathrm{Ag}_{2} \mathrm{O}, \mathrm{AgCl}_{x}^{(x-1)-}$, and $\mathrm{Ag}_{2} \mathrm{~S}$ ) in the aquatic environment. Various environmental factors, such as $\mathrm{pH}$, temperature, dissolved oxygen, ionic strength, and sunlight radiation, can influence the stability and transformations of AgNPs, which subsequently affect the fate and toxicity of AgNPs in the environment. ${ }^{14-17}$ Specifically, as an omnipresent part of natural water, dissolved organic matter (DOM) plays an important role in determining the environ-

Received: August 10, 2017

Revised: November 14, 2017

Accepted: November 22, 2017

Published: November 22, 2017 
mental fate and toxicity of AgNPs. It has been reported that DOM can improve the stability of AgNPs in aquatic media and suppress the $\mathrm{Ag}^{+}$ion release and homoaggregation of AgNPs. ${ }^{18}$ Yang et al. ${ }^{19}$ exposed nematodes to AgNP suspensions with DOM and found that DOM could reduce the toxicity of AgNPs by decreasing the intracellular uptake of AgNPs as a result of the formation of DOM-AgNP composites. Recent studies reported that $\mathrm{Ag}^{+}$can be photoreduced to form AgNPs in river water or synthetic natural water samples containing DOM. ${ }^{20-22}$ The reduction of $\mathrm{Ag}^{+}$was supposed to follow two possible mechanisms: (1) direct charge transfer from the phenol groups in DOM to metal ions by complexation between $\mathrm{Ag}^{+}$and $\mathrm{DOM}^{23,24}$ and (2) mediation by superoxide ions $\left(\mathrm{O}_{2}^{\bullet-}\right)$ produced from photoirradiation of the phenol groups in DOM. $^{22}$ The possible mechanism can be described by the following chemical reactions ${ }^{25}$

$$
\begin{aligned}
& \mathrm{HA}_{\text {red }}+\mathrm{O}_{2} \rightarrow \mathrm{HA}_{\text {ox }}+\mathrm{O}_{2}^{\bullet-} \\
& \mathrm{Ag}^{+}+\mathrm{O}_{2}^{\bullet-} \rightarrow \mathrm{Ag}^{0}(\mathrm{AgNP})+\mathrm{O}_{2}
\end{aligned}
$$

where $\mathrm{HA}_{\text {red }}$ and $\mathrm{HA}_{\mathrm{ox}}$ represent the reduced and oxidized forms of humic acid (HA) as a model DOM, respectively. Yu et al. $^{26}$ reported the transformations between AgNPs and $\mathrm{Ag}^{+}$in DOM-rich water within $48 \mathrm{~h}$. Furtado et al. ${ }^{27}$ investigated the fate of AgNPs in boreal lake mesocosms and found that AgNPs were relatively stable in the lake environment with a half-life of total Ag of $\sim 20$ days, whereas the detailed processes or mechanisms were unclear. Overall, due to the highly dynamic properties of $\mathrm{AgNPs}^{28}$ and complex composition of $\mathrm{DOM}^{29}$ the behaviors of AgNPs in natural water and the underlying mechanisms are still not entirely understood.

Another cause for the poor understanding of environmental behaviors of AgNPs is the shortage of research tools. Although there have been multiple techniques applicable for the characterization of nanoparticles, such as ultraviolet-visible (UV-vis) absorption spectrometry, electron microscopy, and dynamic light scattering (DLS), the information given by these techniques is not sufficient to fully reveal the complex environmental behaviors of AgNPs. In our previous work, we used multicollector inductively coupled plasma mass spectrometry (MC-ICP-MS) to measure the subtle variations in stable isotopic composition of $\mathrm{Ag}$ during different transformation processes of AgNPs in natural water. ${ }^{30} \mathrm{Ag}$ has two naturally occurring stable isotopes $\left({ }^{107} \mathrm{Ag}\right.$ and $\left.{ }^{109} \mathrm{Ag}\right)$ with close abundances (51.8\%:48.2\%). Results illustrated that different transformation processes of AgNPs could cause different $\mathrm{Ag}$ isotope fractionation, and the $\mathrm{Ag}$ isotope fractionation could indicate the presence of concurrent processes and might even distinguish the origins of AgNPs in the environment. Thus, isotope fractionation can be used as a unique tracer for environmental processes, which makes it different from other characterization techniques. This study preliminarily showed the promise of stable isotope fractionation as a new tool to study the nanoparticles in the environment, while the application potential of this tool is yet to be explored.

In the present study, we investigated the persistence of AgNPs and the stabilization mechanism in a HA-containing water. We incubated polyvinylpyrrolidone (PVP)-coated AgNPs as a model type of engineered AgNPs in the presence of different concentrations of HA for up to 14 days. We monitored and characterized the $\mathrm{Ag}$ species by different techniques, including UV-vis absorption spectrometry, transmission electron microscopy (TEM), energy dispersive X-ray spectroscopy (EDS), inductively coupled plasma mass spectrometry (ICP-MS), and MC-ICP-MS. We show that the HAmediated secondary formation of AgNPs is an important mechanism for the stabilization of AgNPs in HA-containing water. Notably, the Ag isotopic analysis by MC-ICP-MS provides strong evidence for the formation of secondary AgNPs. This study not only helps to better understand the behaviors and fate of AgNPs in the environment but also further demonstrates the usefulness of stable isotope fractionation as a new tool for studying nanoparticles in complex systems.

\section{MATERIALS AND METHODS}

2.1. Materials. PVP-AgNPs were purchased from Zhuiguang Technologies (Shanghai, China). The stock solution was stored at $4{ }^{\circ} \mathrm{C}$ in the dark. The AgNP working solution was prepared after ultrafiltration using ultra-15 centrifugal filter units (10 kDa; Millipore, MA, USA) and washed with ultrapure water four times to remove excess $\mathrm{Ag}^{+} . \mathrm{HNO}_{3}$ (65\%) was purchased from Merck (Darmstadt, Germany). Suwannee River humic acid standard II (SRHA) was obtained from the International Humic Substances Society (IHSS, St. Paul, $\mathrm{MN}$ ). The SRHA stock solutions were prepared in ultrapure water, vibrated in a shaker overnight, and then filtered through a $0.45-\mu \mathrm{m}$ filter. Ultrapure water (Merck Millipore, Darmstadt, Germany) was used to prepare all working solutions.

Multielement calibration standard for ICP-MS analysis was purchased from Agilent Technologies (8500-6940 for silver standard and 5188-6525 for internal standard; CA, USA). The Ag isotope standard SRM 978a for MC-ICP-MS measurement was purchased from the National Institute of Standards and Technology (NIST, Gaithersburg, MD). The Pd internal standard was purchased from the Delta Scientific Laboratory Products Ltd. (Mississauga, ON, Canada). All standard solutions were used after dilution with $5 \% \mathrm{HNO}_{3}$.

2.2. Characterization of Silver Nanoparticles. The AgNPs were characterized by a transmission electron microscope (H-7500, Hitachi, Japan) and a high-resolution transmission electron microscope equipped with an energy dispersive X-ray spectrometer (TECANI G20, FEI, Hillsboro, OR). The sample solution was dropped onto the ultrathin carbon-coated copper grid (Zhongjingkeyi Technology Co., Beijing) and dried under an infrared lamp. The AgNP solution was also characterized by a UV-vis spectrometer (Shimadzu UV-3600, Kyoto, Japan).

2.3. The $\mathrm{Ag}^{+}$Release Experiment. The $\mathrm{Ag}^{+}$release experiments were conducted in a solar simulator ( $\mathrm{SN}-500$, Beifang Lihui Instrument Equipment Co., Beijing) equipped with three wind-refrigerated $2500 \mathrm{~W}$ Xe lamps as simulated sunlight sources. The light intensity was maintained at $550 \mathrm{~W} /$ $\mathrm{m}^{2}$, and the temperature was kept at $35 \pm 2{ }^{\circ} \mathrm{C}$. AgNP solutions $(17.0 \mathrm{mg} / \mathrm{L})$ were incubated with a series of concentrations $(0$, $0.1,0.5,1,2,4,8,10,16,20$, and $50 \mathrm{mg} / \mathrm{L})$ of SRHA in $500 \mathrm{~mL}$ beakers for up to 14 days. The dissolved oxygen concentration in the system varied within the range of $4.6-5.0 \mathrm{mg} / \mathrm{L}$. The experiments were also carried out at a lower concentration (1.0 $\mathrm{mg} / \mathrm{L}$ ) of AgNPs. At each time interval, $10 \mathrm{~mL}$ of the samples was collected and centrifuged by an ultrafiltration device (Amicon ultra-15 centrifugal filter units, $10 \mathrm{kDa}$; Millipore, MA, USA) at $8000 \mathrm{~g}$ for $30 \mathrm{~min}$ to separate the dissolved $\mathrm{Ag}^{+}$ions from AgNPs. The ultrafiltration process has been examined to ensure that no significant $\mathrm{Ag}^{+}$loss or artificial $\mathrm{Ag}$ isotope fractionation was caused. ${ }^{30}$ The control experiments were 
performed in the dark by wrapping the beakers with aluminum foil, and other conditions were the same as those in sunlight experiments. All experiments were performed in triplicate $(n=$ 3). Note: the conclusions drawn from sunlight experiments were also validated under real sunlight. Considering that it is impossible to control the real sunlight intensity, data were collected only under simulated sunlight.

2.4. Sample Preparation for ICP-MS Analysis. The concentration of total $\mathrm{Ag}$ and released $\mathrm{Ag}^{+}$was measured by an Agilent Technologies 8800 inductively coupled plasma mass spectrometer (CA, USA). The total Ag content was measured after digestion of the sample with $65 \% \mathrm{HNO}_{3}$ and $\mathrm{H}_{2} \mathrm{O}_{2}$ followed by dilution with $5 \% \mathrm{HNO}_{3}$. The released $\mathrm{Ag}^{+}$samples (containing only $\mathrm{Ag}^{+}$) were directly diluted with $5 \% \mathrm{HNO}_{3}$ for ICP-MS analysis.

2.5. Sample Preparation for Ag Isotope Ratio Measurement by MC-ICP-MS. The Ag isotope ratio was measured by a $\mathrm{Nu}$ II Plasma multicollector inductively coupled plasma mass spectrometer (Wrexham, UK) equipped with 16 Faraday cups and working in low-resolution mode. Each $2 \mathrm{~mL}$ of the residual $\mathrm{AgNP}$ solution and dissolved $\mathrm{Ag}^{+}$samples was digested in a CEM Mars 5 Microwave Reaction System (Matthews, NC) after adding $5 \mathrm{~mL}$ of $65 \% \mathrm{HNO}_{3}$ and $1 \mathrm{~mL}$ of $\mathrm{H}_{2} \mathrm{O}_{2}$. The resulting solution was diluted to a $\mathrm{Ag}$ concentration of about $100 \mu \mathrm{g} / \mathrm{L}$ with $5 \% \mathrm{HNO}_{3}$ for MC-ICP-MS analysis. All liquid samples were introduced by a Desolvation Nebulizer System (DSN-100) using the self-aspiration mode at a flow rate of $0.1 \mathrm{~L} / \mathrm{min}$. The blank signals obtained from $5 \% \mathrm{HNO}_{3}$ were subtracted from all sample and standard signals. Three parallel measurements were made for all samples $(n=3)$.

A $\delta$ value relative to a Ag isotope standard solution (NIST SRM 978a) was used to describe the $\mathrm{Ag}$ isotope ratio $\left({ }^{109} \mathrm{Ag} /{ }^{107} \mathrm{Ag}\right)$ in the sample

$$
\delta^{109 / 107} \mathrm{Ag}=\left(\frac{R_{\mathrm{T}}^{\text {Sample }}}{R_{\mathrm{T}}^{\text {Standard }}}-1\right) \times 1000 \% \text { o }
$$

where $R_{\mathrm{T}}^{\text {Sample }}$ and $R_{\mathrm{T}}^{\text {Standard }}$ are mass bias-corrected (or “"true”) $\mathrm{Ag}$ isotope ratios in the sample and standard, respectively. The $\mathrm{Ag}$ isotope fractionation during a process of AgNPs was described by a $\Delta^{109 / 107} \mathrm{Ag}$ value as follows

$$
\Delta^{109 / 107} \mathrm{Ag}_{\text {product }}=\delta^{109 / 107} \mathrm{Ag}_{\text {product }}-\delta^{109 / 107} \mathrm{Ag}_{\text {initial }}
$$

where $\Delta^{109 / 107} \mathrm{Ag}_{\text {product }}$ represents the $\mathrm{Ag}$ isotope fractionation in the transformation product (released $\mathrm{Ag}^{+}$ions or residual AgNPs) compared to the initial AgNPs. $\delta^{109 / 107} \mathrm{Ag}_{\text {product }}$ and $\delta^{109 / 107} \mathrm{Ag}_{\text {initial }}$ represent the $\mathrm{Ag}$ isotopic compositions of the product and initial AgNPs, respectively.

The mass bias of the ${ }^{109} \mathrm{Ag} /{ }^{107} \mathrm{Ag}$ ratio was corrected based on internal normalization with $\mathrm{Pd}$ (using the ${ }^{108} \mathrm{Pd} /{ }^{106} \mathrm{Pd}$ ratio) combined with a standard-sample-standard bracketing approach without assuming identical mass bias for $\mathrm{Pd}$ and $\mathrm{Ag} .{ }^{31,32}$ Because the true value of the ${ }^{108} \mathrm{Pd} /{ }^{106} \mathrm{Pd}$ ratio was unknown, the certified value of 1.07638 for the ${ }^{107} \mathrm{Ag} /{ }^{109} \mathrm{Ag}$ ratio of SRM 978a was first used to obtain the mass bias-corrected ${ }^{106} \mathrm{Pd} /{ }^{108} \mathrm{Pd}$ ratio in two adjacent SRM 978a standard solutions, and then their average value was used for the correction of the ${ }^{109} \mathrm{Ag} /{ }^{107} \mathrm{Ag}$ ratio in the sample. The correction calculation was based on the Russell exponential fractionation law ${ }^{33}$

$$
R_{\mathrm{M}}=R_{\mathrm{T}} \times\left(\frac{m_{i}}{m_{j}}\right)^{f}
$$

where $R_{\mathrm{M}}$ and $R_{\mathrm{T}}$ represent the measured and mass biascorrected ratios, respectively; $m_{i}$ and $m_{j}$ represent the absolute masses of the isotopes of interest; and $f$ is the mass bias correction factor. ${ }^{106} \mathrm{Cd}$ and ${ }^{108} \mathrm{Cd}$ interferences to ${ }^{106} \mathrm{Pd}$ and ${ }^{108} \mathrm{Pd}$ were mathematically removed using an iterative method described by $\mathrm{Lu}$ et $\mathrm{al}^{30}$ The sample digestion process and matrix effects in the MC-ICP-MS measurement have also been evaluated as in our previous work. ${ }^{30}$ The method uncertainty was $0.04 \%$ o (2SD).

\section{RESULTS AND DISCUSSION}

3.1. $\mathrm{Ag}^{+}$Release Experiment of Silver Nanoparticles. In this study, we used PVP-coated AgNPs as a model type of engineered AgNPs. The PVP-coated AgNPs were characterized by TEM and UV-vis absorption spectroscopy. As shown in Figure 1, TEM measurement showed that the AgNPs were
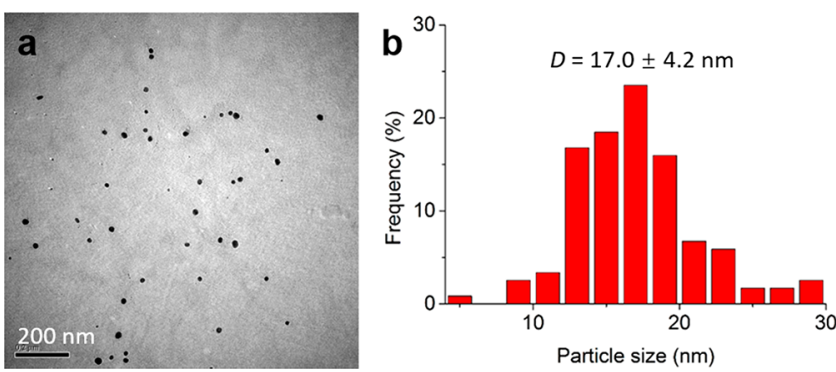

Figure 1. Characterization of PVP-coated AgNPs: (a) a typical TEM image and (b) particle size distribution. The average diameter $(D)$ of AgNPs is $17.0 \pm 4.2 \mathrm{~nm}$. The particle size distribution statistics were counted based on more than 200 particles.

typically spherical and well dispersed in the solution with an average diameter of $17.0 \pm 4.2 \mathrm{~nm}$. The UV-vis spectra showed a maximum absorption band $\left(\lambda_{\max }\right)$ at $\sim 400 \mathrm{~nm}$, corresponding to the characteristic absorption of AgNPs.

In previous studies on the environmental behaviors of AgNPs, environmental factors such as $\mathrm{pH}$, salinity, DOM, and photoradiation have been repeatedly considered, but their roles in determining the fate of AgNPs are still controversial. Here we attempted to get new insights into the effect of DOM on the environmental behaviors of AgNPs. In order to study the persistence of AgNPs in the aquatic environment, we first monitored the variation in the absorption spectra of AgNP suspension in the presence of different concentrations of HA under sunlight. The concentration range of $\mathrm{HA}$ was set to $0-50$ $\mathrm{mg} / \mathrm{L}$, which was accordant with the naturally occurring levels. ${ }^{34}$ Figure $2 \mathrm{a}$ shows that in the absence of HA the characteristic absorption peak of AgNPs at $400 \mathrm{~nm}$ (i.e., $\lambda_{\max }$ ) gradually declined and almost disappeared after $336 \mathrm{~h}$, clearly indicating the dissolution of AgNPs to release $\mathrm{Ag}^{+}$ions in the solution. A broad peak at $\sim 500 \mathrm{~nm}$ appeared after $168 \mathrm{~h}$ photoradiation probably due to the slight aggregation of AgNPs. ${ }^{35,36}$ The aggregation of AgNPs also caused the color of the solution to turn from yellow to light purple (Figure S1). While in the presence of HA beyond $1 \mathrm{mg} / \mathrm{L}$ (e.g., Figure $2 \mathrm{~b}$ and $2 c$ ), the $\lambda_{\max }$ absorbance of AgNPs showed no evident decrease compared with the control without HA, suggesting that the presence of $\mathrm{HA}$, even at a low concentration, could 

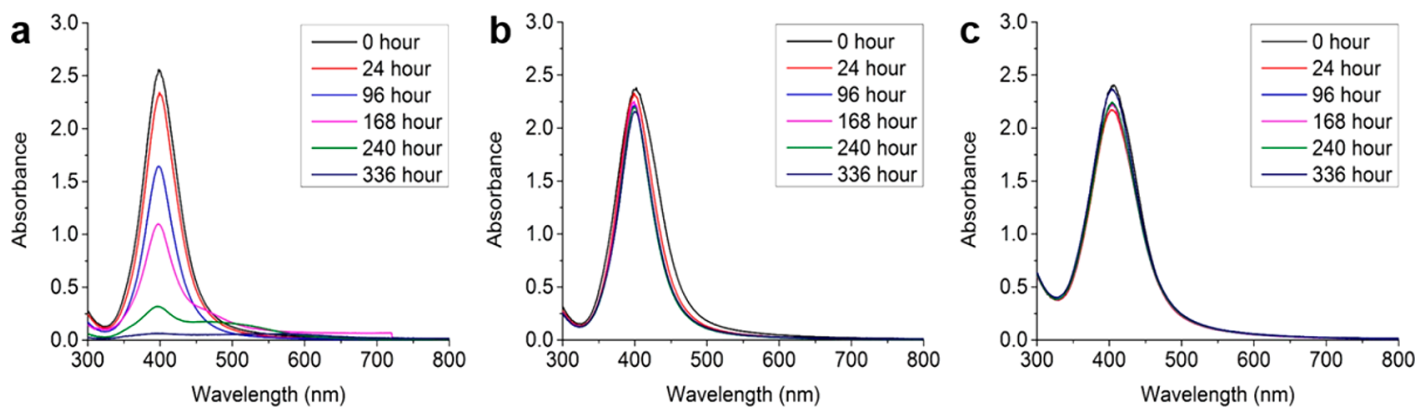

Figure 2. UV-vis absorption spectra of AgNP suspension after incubation with HA for $336 \mathrm{~h}$ under sunlight: (a) $0 \mathrm{mg} / \mathrm{L} \mathrm{HA}$, (b) $1 \mathrm{mg} / \mathrm{L} \mathrm{HA}$, and (c) $20 \mathrm{mg} / \mathrm{L}$ HA. AgNP concentration: $17.0 \mathrm{mg} / \mathrm{L}$. The UV-vis absorbance of the solution was recorded at an interval of $24 \mathrm{~h}$.
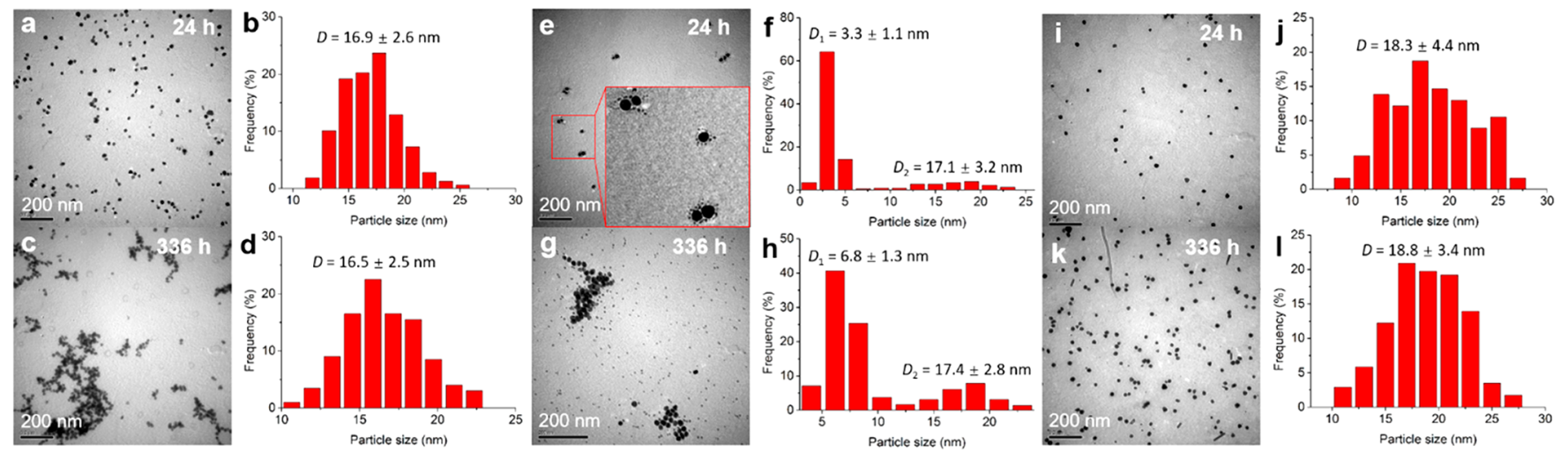

Figure 3. Typical TEM images and corresponding particle size distribution of AgNPs incubated with 0 , 1, and $20 \mathrm{mg} / \mathrm{L}$ of $\mathrm{HA}$ under sunlight for 24 and $336 \mathrm{~h}$ : (a-d) AgNP solution incubated with no HA for $24 \mathrm{~h}(\mathrm{a}, \mathrm{b})$ and $336 \mathrm{~h}(\mathrm{c}, \mathrm{d}) ;(\mathrm{e}-\mathrm{h})$ AgNP solution exposed to $1 \mathrm{mg} / \mathrm{L} \mathrm{HA}$ for $24 \mathrm{~h}$ (e, $\mathrm{g}$ ) and $336 \mathrm{~h}$ (f, h); AgNP solution exposed to $20 \mathrm{mg} / \mathrm{L} \mathrm{HA}$ for $24 \mathrm{~h}(\mathrm{i}, \mathrm{k})$ and $336 \mathrm{~h}(\mathrm{j}, \mathrm{l})$. AgNP concentration: 17.0 mg/L. D: average diameter of particles. The particle size distribution statistics were counted based on more than 200 particles. The inset in (e) shows the high-resolution image for the secondarily formed "satellite" particles surrounding the primary AgNPs.
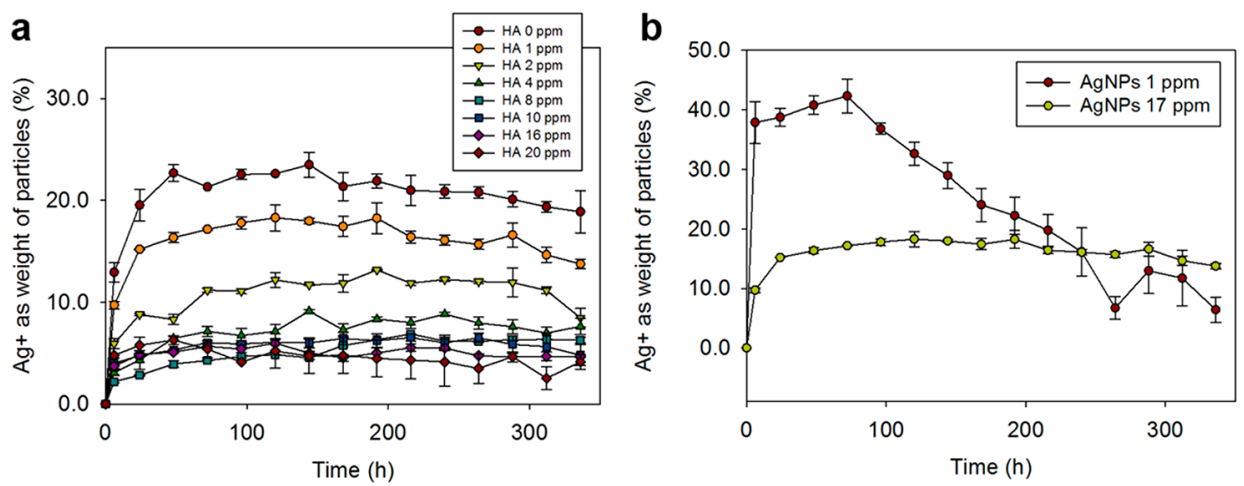

Figure 4. The $\mathrm{Ag}^{+}$release kinetics from AgNPs during a $336 \mathrm{~h}$ incubation under sunlight. (a) Effect of $\mathrm{HA}$ concentration on the $\mathrm{Ag}^{+}$release kinetics of AgNPs. AgNP concentration: $17.0 \mathrm{mg} / \mathrm{L}$. (b) Effect of AgNP concentration on the $\mathrm{Ag}^{+}$release kinetics of AgNPs. HA concentration: $1 \mathrm{mg} / \mathrm{L}$. The error bars represent 1 SD from three parallel experiments $(n=3)$.

strongly suppress the dissolution of AgNPs and the release of $\mathrm{Ag}^{+}$. The results for more $\mathrm{HA}$ concentrations are given in Figure S2. During the incubation process, the $\mathrm{pH}$ of the solution could keep relatively stable (see Figure S3). We also repeated the experiments at a lower concentration $(1.0 \mathrm{mg} / \mathrm{L}$; see Figure S4) and with a larger particle size of AgNPs (39.0 \pm $3.3 \mathrm{~nm}$; see Figures S5 and S6). Results showed that the $\lambda_{\max }$ absorbance of AgNPs at a low concentration decreased more quickly within the first $24 \mathrm{~h}$ than that at a high AgNP concentration (Figure S4) and that large AgNPs had a higher persistence than small particles in the presence of HA (Figure S6). We also found that the stabilizing ability of HA for AgNPs could be maintained even in the presence of $10 \mathrm{mM} \mathrm{Na}^{+}$or $\mathrm{Ca}^{2+}$ ions (Figure S7).

We further characterized the AgNP suspension after photoradiation for periods of time up to $336 \mathrm{~h}$ by TEM. The results are shown in Figure 3. TEM measurements showed that AgNPs in the absence of HA intensively aggregated after a 336 $\mathrm{h}$ incubation (Figure 3c), which could account for the broad peak appearing at $\sim 500 \mathrm{~nm}$ in UV-vis absorption spectra (Figure 2a). In the presence of a low concentration of HA (e.g., $1 \mathrm{mg} / \mathrm{L}$ ), the aggregation was effectively inhibited with a large number of small particles remaining in the solution (Figure 3g). With further increasing the HA concentration to higher levels 


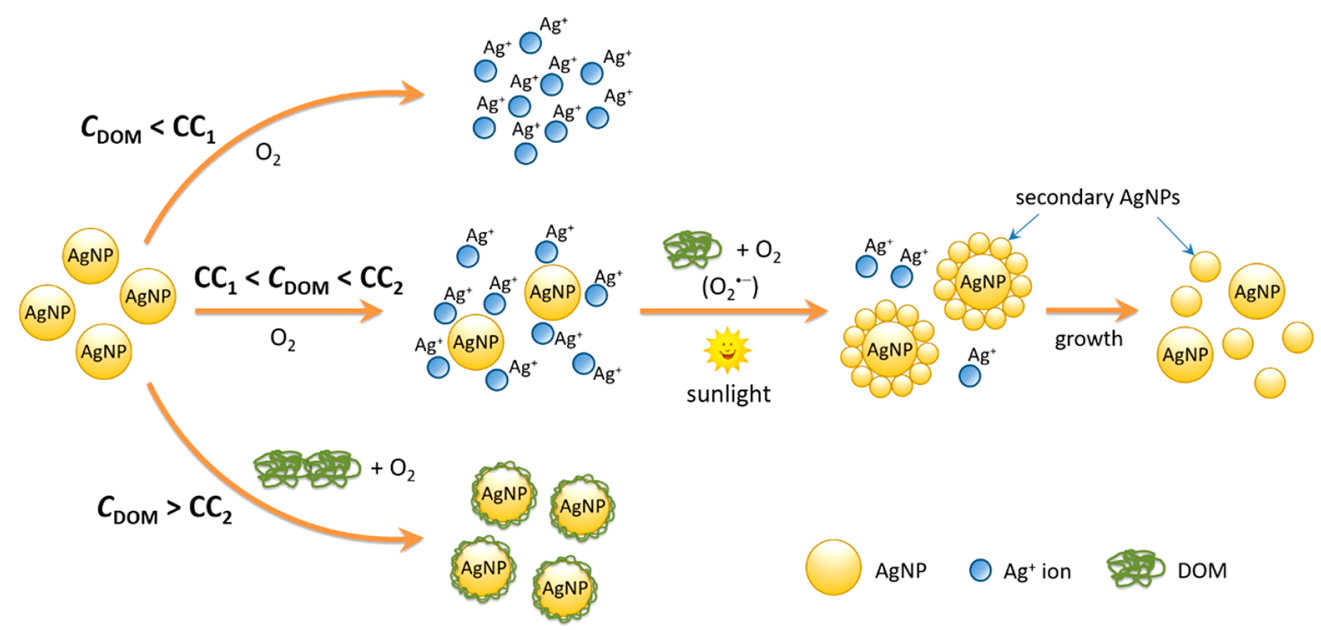

Figure 5. Scheme showing the possible mechanisms for the HA-dependent persistence of AgNPs in water.

(e.g., $20 \mathrm{mg} / \mathrm{L}$ ), the aggregation of AgNPs was thoroughly suppressed, and no obvious change in particle size (from $18.3 \pm$ $4.4 \mathrm{~nm}$ to $18.8 \pm 3.4 \mathrm{~nm}$ ) or shape was observed after a $336 \mathrm{~h}$ incubation (Figure $3 \mathrm{k}$ and $3 \mathrm{l}$ ), suggesting that a high concentration of HA could stabilize the AgNPs long-term in the aquatic environment. ${ }^{27}$

Noteworthily, we found that in the presence of a low concentration (e.g., $1 \mathrm{mg} / \mathrm{L}$ ) of HA, a large number of small "satellite" particles with mean particle size of $3.3 \pm 1.1 \mathrm{~nm}$ appeared and closely surrounded the original AgNPs after a 24 $\mathrm{h}$ incubation (Figure 3e). When further prolonging the incubation time to $336 \mathrm{~h}$, the "satellite" particles surrounding the AgNPs disappeared; instead, many small particles were observed in the bulk solution. These small particles showed a slight growth in mean particle size compared with the "satellite" nanoparticles from $3.3 \pm 1.1 \mathrm{~nm}$ to $6.8 \pm 1.3 \mathrm{~nm}$ (Figure $3 \mathrm{f}$ and $3 \mathrm{~h}$ ). This eventually resulted in a redistribution in particle size in the solution. As shown in Figure $3 \mathrm{~h}$, a portion of particles (23.7\%) kept the same diameter as the original AgNPs (17.4 \pm $2.8 \mathrm{~nm}$ ), while the other portion of particles $(76.3 \%)$ was in a diameter of $6.8 \pm 1.3 \mathrm{~nm}$. Furthermore, high-resolution TEM and EDS measurements were used to characterize the AgNPs, and results confirmed that the newly formed particles were $\mathrm{Ag}$ nanoparticles (Figures S8 and S9). The TEM results obtained at more HA concentrations $(2,4,8$, and $16 \mathrm{mg} / \mathrm{L})$ are given in Figure S10.

In order to obtain quantitative data, the release of $\mathrm{Ag}^{+}$from AgNPs was also monitored by using ICP-MS. The PVP-coated AgNPs were used immediately after washing with ultrapure water several times to remove excess $\mathrm{Ag}^{+}$ions, so the initial $\mathrm{Ag}^{+}$ was regarded as zero. In the AgNP solution with no HA (Figure $4 \mathrm{a})$, the mass percentage of the released $\mathrm{Ag}^{+}$increased rapidly during the first $48 \mathrm{~h}$ (reach 23\%) and then leveled off. ${ }^{37-39}$ The slight decrease of $\mathrm{Ag}^{+}$after $192 \mathrm{~h}$ might be ascribed to the readsorption of $\mathrm{Ag}^{+}$to $\mathrm{AgNPs}$ and photoreduction of $\mathrm{Ag}^{+}$ ions, ${ }^{30}$ which generated some precipitates with metallic luster at the inner wall of the container and the surface of the solution. In the presence of $1 \mathrm{mg} / \mathrm{L} \mathrm{HA}$, the release profile of $\mathrm{Ag}^{+}$was similar to that without HA, but the release amount was lower (the maximum release percentage was $18 \%$ ). While the concentration of HA increased to higher levels, the release amount of $\mathrm{Ag}^{+}$was greatly reduced to very low levels (e.g., 6\% for $10 \mathrm{mg} / \mathrm{L} \mathrm{HA}$ and $5 \%$ for $20 \mathrm{mg} / \mathrm{L} \mathrm{HA}$ ). Furthermore, we also monitored the $\mathrm{Ag}^{+}$release at a lower $\mathrm{AgNP}$ concentration
$(1.0 \mathrm{mg} / \mathrm{L}$ ). The release curve (Figure $4 \mathrm{~b}$ ) showed that the mass fraction of the released $\mathrm{Ag}^{+}$at a lower AgNP concentration was higher (the maximum release percentage reached 43\%) than that at a higher AgNP concentration. Because the $\mathrm{Ag}^{+}$release with a high concentration of AgNPs can be inhibited by multiple factors, such as reaction-induced proton depletion, oxygen depletion, and surface reaction inhibition, the first-order rate constant of $\mathrm{Ag}^{+}$release decreased with the initial AgNP concentration increasing. ${ }^{14}$ After a $72 \mathrm{~h}$ incubation, the $\mathrm{Ag}^{+}$release began to decrease which was due probably to the reduction of $\mathrm{Ag}^{+}$by $\mathrm{HA}$.

We also carried out control experiments in the dark (see Figure S11) using $\mathrm{Ag}^{+}$instead of AgNPs (see Figure S12). With $1 \mathrm{mg} / \mathrm{L} \mathrm{HA}$ in dark conditions, $\mathrm{Ag}^{+}$was continuously released from AgNPs with no small particles being formed in the solution (Figure S11). When using $\mathrm{Ag}^{+}$instead of AgNPs, the $\mathrm{Ag}^{+}$could be reduced to form particles with the characteristic absorption peak of AgNPs (Figure S12), which was consistent with that observed in previous reports. ${ }^{21,22,30}$

3.2. Mechanism for the HA-Dependent Persistence of AgNPs in Water. Based on the results mentioned above, we propose the possible mechanism for the HA-dependent persistence of AgNPs in water as depicted in Figure 5. Depending on the concentration of HA, AgNPs show distinctly different behaviors and fates. Generally, three types of mechanisms may be responsible for the observed phenomena:

(1) With no HA or an extremely low concentration of HA, a portion of AgNPs in the solution can be dissolved into $\mathrm{Ag}^{+}$ions by photo-oxidation as indicated by the $\mathrm{Ag}^{+}$release curve in Figure 4a. The other portion of AgNPs can aggregate into large particles (as illustrated by Figure 3c) or transform into $\mathrm{Ag}^{0}$ precipitates via the photoreduction of $\mathrm{Ag}^{+}$ions, and almost no AgNPs ultimately remain in the solution (as indicated by the absence of the characteristic absorption peak of AgNPs after $336 \mathrm{~h}$ as shown in Figure 2a).

(2) With a low concentration of HA (e.g., $1 \mathrm{mg} / \mathrm{L}$ ), the $\mathrm{Ag}^{+}$ release and aggregation of AgNPs can be partly inhibited, and AgNPs can persist in the aquatic environment for a relatively long period of time. Interestingly, we observed the formation of numerous small particles and the redistribution of particle size of AgNPs (see Figure $3 \mathrm{e}-\mathrm{h}$ ). As mentioned above, HA can reduce $\mathrm{Ag}^{+}$ions to form AgNPs under natural conditions. ${ }^{20-22}$ Therefore, we suggest that the small particles observed in Figure $3 \mathrm{e}$ and $3 \mathrm{~g}$ should be secondary AgNPs formed by the 

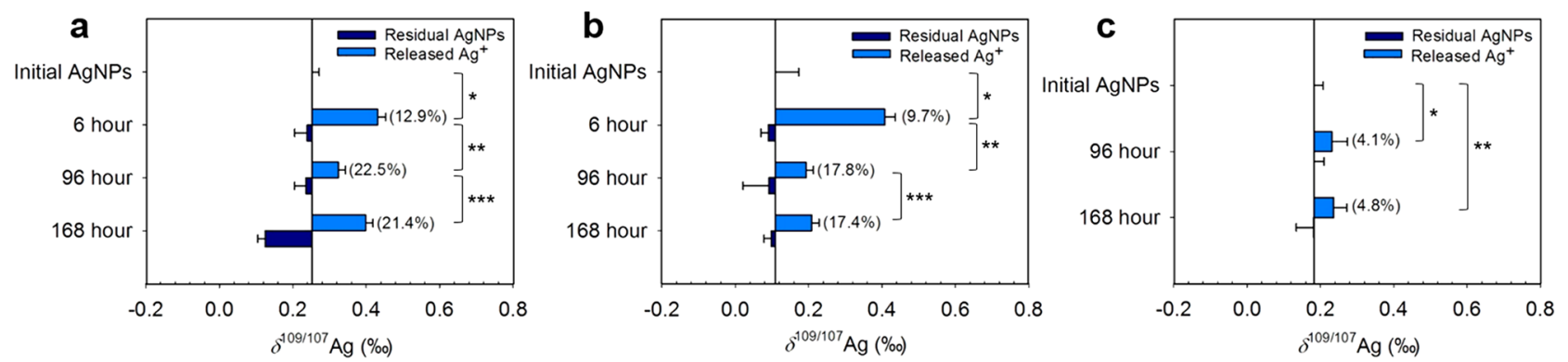

Figure 6. Ag isotope fractionation during the $\mathrm{Ag}^{+}$release process from $\mathrm{AgNPs}$ under sunlight in the presence of $\mathrm{HA}:(\mathrm{a}) \mathrm{HA}=0 \mathrm{mg} / \mathrm{L}, * P<0.001$, $* * P<0.01, * * * P<0.001$; (b) $\mathrm{HA}=1 \mathrm{mg} / \mathrm{L}, * P<0.001$, ** $P<0.001$, ***P=0.38; (c) HA $=20 \mathrm{mg} / \mathrm{L}, * P=0.19$, ** $P=0.14$. The bars start from the $\delta^{109 / 107} \mathrm{Ag}$ value of the initial AgNPs. The percentages in parentheses represent the mass percentages of released $\mathrm{Ag}^{+}$in the total Ag. The data are also given in Tables S1-S3 in the SI to make a mass balance calculation. The error bars represent 1 SD from three parallel experiments $(n=3)$.

reduction of $\mathrm{Ag}^{+}$ions with $\mathrm{HA}$ induced by sunlight. That is, the $\mathrm{Ag}^{+}$released from primary AgNPs can be reduced back with $\mathrm{HA}$ under sunlight to regenerate AgNPs (i.e., secondary AgNPs). This mechanism can well explain the TEM results in Figure $3 \mathrm{e}$ and $3 \mathrm{~g}$. The photo-oxidative release of $\mathrm{Ag}^{+}$can cause a concentration gradient of $\mathrm{Ag}^{+}$around the AgNPs, and the $\mathrm{Ag}^{+}$ concentration near the surface of AgNPs should be higher than that in the bulk solution, so the secondary particles are formed first around the primary AgNPs (i.e., the "satellite" particles shown in Figure 3e) and then dispersed to the bulk solution with a slight size growth. The formation of new nanoparticles also explained the slight increase of $\lambda_{\max }$ absorbance of AgNPs with $1 \mathrm{mg} / \mathrm{L} \mathrm{HA}$ in Figure $2 \mathrm{~b}$.

(3) With a high concentration of HA (e.g., $20 \mathrm{mg} / \mathrm{L}$ ), HA can tightly wrap the primary AgNPs due to the high affinity of AgNPs for $\mathrm{HA}^{40,41}$ and greatly suppress the $\mathrm{Ag}^{+}$release. Thus, the primary particles can keep stable in the solution long-term with no significant change in particle size or morphology.

These mechanisms were also supported by the control experiments in dark conditions (see Figure S11) and with $\mathrm{Ag}^{+}$ instead of AgNPs (see Figure S12). In dark conditions, $\mathrm{Ag}^{+}$was continuously released from AgNPs, and no secondary particles were found in the solution, also suggesting that the secondary AgNPs were produced by the sunlight-induced $\mathrm{Ag}^{+}$reduction with $\mathrm{HA}$; and with $\mathrm{Ag}^{+}$only, the formation of nanoparticles proved the reducing ability of $\mathrm{HA}$ toward $\mathrm{Ag}^{+}$under natural conditions.

From the discussion above, we can learn that there are two critical HA concentrations that affect the long-term persistence of AgNPs in the HA-containing water (see Figure 5). The first critical concentration $\left(\mathrm{CC}_{1}\right)$ determines whether the AgNPs can persist in the water, and the second critical concentration $\left(\mathrm{CC}_{2}\right)$ determines whether the AgNPs can maintain their particle size. Specifically, for HA concentration $\left(C_{\mathrm{HA}}\right)<\mathrm{CC}_{1}$, AgNPs will ultimately transform into other forms of $\mathrm{Ag}$ via photo-oxidation release of $\mathrm{Ag}^{+}$ions; for $\mathrm{CC}_{1}<C_{\mathrm{HA}}<\mathrm{CC}_{2}$, AgNPs can persist in the water due to the secondary formation of AgNPs mediated by HA and sunlight, but the particle size of AgNPs may rearrange; and for $C_{\mathrm{HA}}>\mathrm{CC}_{2}$, the AgNPs can persist in the water long-term with no significant change of particle size. To the best of our knowledge, this may be the first demonstration of the role of secondary particle formation in the persistence of AgNPs in an aquatic system. It should be noted that the values of the two critical HA concentrations are closely dependent on the intrinsic properties of AgNPs (e.g., particle size) and environmental factors (e.g., $\mathrm{pH}$, salinity, sunlight, etc.). In this study, the $\mathrm{CC}_{1}$ and $\mathrm{CC}_{2}$ were regarded to be 1 and
$20 \mathrm{mg} / \mathrm{L}$, respectively, and their values may vary in other systems.

3.3. Evidence from $\mathrm{Ag}$ Isotope Fractionation during the $\mathrm{Ag}^{+}$Release Process of AgNPs. Although the characterization techniques used above such as absorption spectrometry and TEM can well characterize the nanoparticles, they do not give direct evidence for the processes. Therefore, to verify the proposed mechanisms in Figure 5, we further investigated the $\mathrm{Ag}$ isotope fractionation during the $\mathrm{Ag}^{+}$release process of AgNPs in the presence of different concentrations of HA. In our previous work, ${ }^{30}$ we have demonstrated that natural stable isotope fractionation can be used as a new means to study environmental processes of nanoparticles. The different environmental processes of AgNPs can cause different $\mathrm{Ag}$ isotope fractionation signatures, which can be used as unique tracers to indicate the processes that the nanoparticles have undergone. For instance, the HA-mediated reduction of $\mathrm{Ag}^{+}$ can cause a significant enrichment of ${ }^{109} \mathrm{Ag}$ in the produced AgNPs with an isotopic enrichment factor $(\varepsilon)$ up to $0.86 \%$ o. $^{30}$ This value is at the same level as the largest variations in the ${ }^{109} \mathrm{Ag} /{ }^{107} \mathrm{Ag}$ ratio found in terrestrial samples. ${ }^{31,32,42}$ Notably, the natural isotopic information is independent of the concentration of element or particle size, and thus it can provide additional evidence for the studied processes. For this consideration, here we also used $\mathrm{Ag}$ isotope fractionation as a tracer to study the processes in the persistence of AgNPs at different HA concentrations.

The Ag isotope fractionation during the dissolution of AgNPs with different concentrations of HA is shown in Figure 6. All the data followed isotope mass balance (see Tables S1S3). In the AgNP solution without HA (Figure 6a), the relative fraction of $\mathrm{Ag}^{+}$released was in the range of $12.93-21.36 \%$. At the first $6 \mathrm{~h}$, the dissolution of AgNPs caused a significant $\mathrm{Ag}$ isotope fractionation $\left(\Delta^{109 / 107} \mathrm{Ag}_{\text {release }}=0.18 \%\right.$; $\left.* P<0.001\right)$ with ${ }^{109} \mathrm{Ag}$ being enriched in the released $\mathrm{Ag}^{+}$. This phenomenon was consistent with that observed previously ${ }^{30}$ and could be explained by the formation of an intermediate metal oxide phase (e.g., $\mathrm{Ag}_{2} \mathrm{O}$ ) at the surface of $\mathrm{AgNPs}$ via photo-oxidation. ${ }^{43,44}$ Following the equilibrium isotope fractionation rules, ${ }^{45}$ the heavier isotope was prone to being enriched in a phase with a higher oxidation state. Thus, the metal oxide phase should be enriched in ${ }^{109} \mathrm{Ag}$, causing the released $\mathrm{Ag}^{+}$to be enriched in ${ }^{109} \mathrm{Ag}$. As the incubation time increased to $96 \mathrm{~h}$, the degree of $\mathrm{Ag}$ isotope fractionation was mitigated compared with that at $6 \mathrm{~h}\left(\Delta^{109 / 107} \mathrm{Ag}_{\text {release }}=0.07 \%\right.$ for $96 \mathrm{~h}$; $* * P<$ $0.01)$. The mitigation of the fractionation at a longer incubation time was suggested to be caused by the photoreduction of $\mathrm{Ag}^{+}$ 
ions, in which ${ }^{109} \mathrm{Ag}$ was prone to be enriched in the $\mathrm{Ag}^{0}$ precipitates, ${ }^{30}$ thus depleting the ${ }^{109} \mathrm{Ag}$ in the released $\mathrm{Ag}^{+}$. This was also supported by the control experiment in the dark (Figure S13). It should be noted that the degree of the $\mathrm{Ag}$ isotope fractionation is affected by the relative fraction reacted. ${ }^{45}$ From 96 to $168 \mathrm{~h}$, although the relative fraction of released $\mathrm{Ag}^{+}$did not change much (22.5\% to $21.4 \%$ ), the residual AgNPs kept dissolving, and a large portion (56.8\%) of total $\mathrm{Ag}$ was transformed into $\mathrm{Ag}^{0}$ precipitates (see Table $\mathrm{S} 1$ ), which caused the $\delta^{109 / 107} \mathrm{Ag}$ value of the residual AgNPs to continue to shift negatively $\left(\Delta^{109 / 107} \mathrm{Ag}_{\text {residual }}=-0.13 \%\right.$ o $)$. Thus, to maintain the isotopic mass balance in the system (see Table S1), the $\delta^{109 / 107} \mathrm{Ag}$ value of the released $\mathrm{Ag}^{+}$increased again.

In the case of $1 \mathrm{mg} / \mathrm{L} \mathrm{HA}$ (Figure $6 \mathrm{~b}$ ), a large $\mathrm{Ag}$ isotope fractionation was obtained at $6 \mathrm{~h}$ with $9.7 \%$ of AgNPs being dissolved and the released $\mathrm{Ag}^{+}$being significantly enriched in ${ }^{109} \mathrm{Ag}\left(\Delta^{109 / 107} \mathrm{Ag}_{\text {release }}=0.30 \%\right.$; $\left.* P<0.001\right)$. When the incubation time increased to $96 \mathrm{~h}$, the reactive fraction of released $\mathrm{Ag}^{+}$increased to $17.8 \%$, and the $\delta^{109 / 107} \mathrm{Ag}$ value of released $\mathrm{Ag}^{+}$greatly shifted negatively $\left(\Delta^{109 / 107} \mathrm{Ag}_{\text {release }}=\right.$ $0.08 \% 0)$ compared with that at $6 \mathrm{~h}(* * P<0.001)$, indicating a remarkable loss of ${ }^{109} \mathrm{Ag}$ in the released $\mathrm{Ag}^{+}$. Such a variation in $\delta^{109 / 107} \mathrm{Ag}$ was much larger than that obtained without HA (Figure 6a) and could not be ascribed to the photoreduction of $\mathrm{Ag}^{+}$ions. ${ }^{30}$ As mentioned above, the HA-mediated reduction of $\mathrm{Ag}^{+}$to generate AgNPs can cause a significant $\mathrm{Ag}$ isotope fractionation with the formed AgNPs being enriched in ${ }^{109} \mathrm{Ag}$ and the residual $\mathrm{Ag}^{+}$being enriched in ${ }^{107} \mathrm{Ag}^{30}$ This effect highly matched the variation in $\delta^{109 / 107} \mathrm{Ag}$ of the released $\mathrm{Ag}^{+}$ upon the incubation time increasing, suggesting the occurrence of the HA-mediated reduction of $\mathrm{Ag}^{+}$in the system. Therefore, the $\mathrm{Ag}$ isotope fractionation provided clear evidence for the HA-mediated secondary formation of AgNPs from the released $\mathrm{Ag}^{+}$. After $168 \mathrm{~h}$, the $\delta^{109 / 107} \mathrm{Ag}$ of released $\mathrm{Ag}^{+}\left(\Delta^{109 / 107} \mathrm{Ag}_{\text {release }}\right.$ $=0.10 \%$ ) and the relative fraction of $\mathrm{Ag}^{+}$released (from $17.8 \%$ to $17.4 \%$ ) remained unchanged compared with that at $96 \mathrm{~h}$ $(* * * P=0.38)$, suggesting that the experimental system had reached an equilibrium within $96 \mathrm{~h}$.

In the presence of a high concentration of HA (e.g., $20 \mathrm{mg}$ / $\mathrm{L}$; Figure 6c), the $\mathrm{Ag}^{+}$release was strongly inhibited, and the relative fraction of released $\mathrm{Ag}^{+}$was kept to very low levels ( $4.1 \%$ for $96 \mathrm{~h}$ and $4.8 \%$ for $168 \mathrm{~h}$ ). No significant $\mathrm{Ag}$ isotope fractionation was observed during the whole incubation process $\left(\Delta^{109 / 107} \mathrm{Ag}_{\text {release }}=0.05 \%\right.$ or for $96 \mathrm{~h}(* P=0.19)$ and $0.05 \%$ or $168 \mathrm{~h}(* * P=0.14))$. This result demonstrated that AgNPs were in a relatively steady state in the presence of a high concentration of HA. Specifically, the absence of $\mathrm{Ag}$ isotope fractionation suggested that the $\mathrm{Ag}^{+}$release was directly suppressed by the high concentration of HA rather than being in situ reduced, otherwise the HA-mediated reduction of $\mathrm{Ag}^{+}$would cause significant $\mathrm{Ag}$ isotope fractionation. Overall, the results of $\mathrm{Ag}$ isotope fractionation in Figure $6 \mathrm{a}-\mathrm{c}$ strongly evidenced the proposed mechanism in Figure 5 for the persistence of AgNPs in the HA-containing water.

3.4. Environmental Implications. The environmental fate of AgNPs is highly relevant for their risk assessment for ecosystems and human health. So far, engineered AgNPs discharged to the environmental sewer water system are usually thought to end up in wastewater treatment plants (WWTPs), ${ }^{46,47}$ deposited in sludge, and finally transformed to $\mathrm{Ag}_{2} \mathrm{~S}$ as a stable form and transport in ecosystems. ${ }^{48,49}$ However, recent studies also found that $\mathrm{Ag}_{2} \mathrm{~S}$ can further transform into other Ag species or even regenerate AgNPs in some environmental conditions, such as in the presence of an environmentally relevant concentration of Fe(III). ${ }^{50}$ This calls for reconsideration of the lifecycle of AgNPs in the environment. Furthermore, a considerable mass of engineered AgNPs is being directly discharged into natural waters besides waste management systems. ${ }^{51}$ The present study demonstrates that AgNPs may persist in HA-containing waters for longer periods of time than expected, even with a low concentration of HA. The detailed interpretation on the role of $\mathrm{HA}$ in the persistence of AgNPs will help understand the environmental fate and assess the impacts of AgNPs on the ecosystems. For instance, the particle size redistribution caused by the secondary particle formation should be considered in the risk assessment of AgNPs for aquatic ecosystems, because the toxicity of AgNPs is size-dependent. ${ }^{52}$

It is worth noting that the HA-mediated secondary particle formation of AgNPs relies on the dissolved oxygen and sunlight. Despite the high affinity of Ag for reduced sulfur, this reaction is highly possible to occur in surface waters, because surface waters are usually saturated with oxygen absorbed from the atmosphere and from the photosynthesis of algae. The dissolved oxygen can oxidize the reduced sulfur ${ }^{53}$ and facilitate the HA-mediated reduction of $\mathrm{Ag}^{+}$(see Figure 5). It should also be noted that the transformations of AgNPs in real aquatic environments are extremely complicated and affected by many factors. For instance, at a naturally occurring concentration of $\mathrm{Cl}, \mathrm{Ag}^{+}$can be transformed into $\mathrm{AgCl}_{x}^{(x-1)-}$ soluble species, ${ }^{54}$ which may mitigate the reduction of $\mathrm{Ag}^{+}$. This study only highlights the role of HA. The roles of other environmental factors and how the critical concentrations of DOM are affected by other factors need to be clarified in future studies.

Another significance of this study is the successful use of stable isotope fractionation as a new tool to unravel the complex environmental processes of AgNPs. On one hand, isotopic analysis can provide extra information in addition to the concentration of element and particle size; on the other hand, the isotopic mass balance calculation ensures a more reliable investigation on the studied system. This tool requires no artificial or radioactive tracers, and thereby it is particularly suitable for studying real environmental systems. However, the application of this tool in a real environment is still limited by the insufficient sensitivity of instrument (i.e., MC-ICP-MS) and analytical capability for complex samples. Therefore, the power of this tool in environmental nano research needs to be further explored by continued efforts on technical improvement in the instrument and expanded applications to more types of nanoparticles.

\section{ASSOCIATED CONTENT}

\section{Supporting Information}

The Supporting Information is available free of charge on the ACS Publications website at DOI: 10.1021/acs.est.7b04115.

$$
\text { Figures S1-S13 and Tables S1-S4 (PDF) }
$$

\section{AUTHOR INFORMATION}

\section{Corresponding Author}

*Phone +86-10-62849124. Fax: +82-10-62849339. E-mail: qianliu@rcees.ac.cn. Corresponding author address: 18 Shuangqing Road, Haidian District, Beijing 100085, China.

ORCID

Lixi Zeng: 0000-0002-4815-3431 
Qian Liu: 0000-0001-8525-7961

\section{Notes}

The authors declare no competing financial interest.

\section{ACKNOWLEDGMENTS}

This work was financially supported by the Chinese Academy of Sciences (No. XDB14010400, QYZDB-SSW-DQC018), the National Basic Research Program of China (2015CB931903, 2015CB932003), and the National Natural Science Foundation of China (No. 91543104, 21377141, 21422509). Q.L. acknowledges the support from the Youth Innovation Promotion Association of CAS.

\section{REFERENCES}

(1) Prabhu, S.; Poulose, E. K. Silver nanoparticles: mechanism of antimicrobial action, synthesis, medical applications, and toxicity effects. Int. Nano Lett. 2012, 2 (1), 1-10.

(2) Rai, M.; Yadav, A.; Gade, A. Silver nanoparticles as a new generation of antimicrobials. Biotechnol. Adv. 2009, 27 (1), 76-83.

(3) Morones, J. R.; Elechiguerra, J. L.; Camacho, A.; Holt, K.; Kouri, J. B.; Ramírez, J. T.; Yacaman, M. J. The bactericidal effect of silver nanoparticles. Nanotechnology 2005, 16 (10), 2346.

(4) Gottschalk, F.; Nowack, B. The release of engineered nanomaterials to the environment. J. Environ. Monit. 2011, 13 (5), $1145-1155$.

(5) Benn, T. M.; Westerhoff, P. Nanoparticle silver released into water from commercially available sock fabrics. Environ. Sci. Technol. 2008, 42 (11), 4133-4139.

(6) Quadros, M. E.; Marr, L. C. Silver nanoparticles and total aerosols emitted by nanotechnology-related consumer spray products. Environ. Sci. Technol. 2011, 45 (24), 10713-10719.

(7) Sung, J. H.; Ji, J. H.; Park, J. D.; Yoon, J. U.; Kim, D. S.; Jeon, K. S.; Song, M. Y.; Jeong, J.; Han, B. S.; Han, J. H. Subchronic inhalation toxicity of silver nanoparticles. Toxicol. Sci. 2009, 108 (2), 452-461.

(8) Kim, Y. S.; Kim, J. S.; Cho, H. S.; Rha, D. S.; Kim, J. M.; Park, J. D.; Choi, B. S.; Lim, R.; Chang, H. K.; Chung, Y. H. Twenty-eight-day oral toxicity, genotoxicity, and gender-related tissue distribution of silver nanoparticles in Sprague-Dawley rats. Inhalation Toxicol. 2008, 20 (6), 575-583.

(9) Arora, S.; Jain, J.; Rajwade, J. M.; Paknikar, K. M. Cellular responses induced by silver nanoparticles: In vitro studies. Toxicol. Lett. 2008, 179 (2), 93-100.

(10) AshaRani, P.; Low Kah Mun, G.; Hande, M. P.; Valiyaveettil, S. Cytotoxicity and genotoxicity of silver nanoparticles in human cells. ACS Nano 2009, 3 (2), 279-290.

(11) Navarro, E.; Piccapietra, F.; Wagner, B.; Marconi, F.; Kaegi, R.; Odzak, N.; Sigg, L.; Behra, R. Toxicity of silver nanoparticles to Chlamydomonas reinhardtii. Environ. Sci. Technol. 2008, 42 (23), 8959-8964.

(12) Smetana, A. B.; Klabunde, K. J.; Marchin, G. R.; Sorensen, C. M. Biocidal activity of nanocrystalline silver powders and particles. Langmuir 2008, 24 (14), 7457-7464.

(13) Wen, R.; Yang, X.; Hu, L.; Sun, C.; Zhou, Q.; Jiang, G. Braintargeted distribution and high retention of silver by chronic intranasal instillation of silver nanoparticles and ions in Sprague-Dawley rats. J. Appl. Toxicol. 2016, 36 (3), 445-453.

(14) Liu, J.; Hurt, R. H. Ion release kinetics and particle persistence in aqueous nano-silver colloids. Environ. Sci. Technol. 2010, 44 (6), 2169-2175.

(15) Zook, J. M.; Long, S. E.; Cleveland, D.; Geronimo, C. L. A.; MacCuspie, R. I. Measuring silver nanoparticle dissolution in complex biological and environmental matrices using UV-visible absorbance. Anal. Bioanal. Chem. 2011, 401 (6), 1993-2002.

(16) Ho, C.-M.; Wong, C.-K.; Yau, S. K.-W.; Lok, C.-N.; Che, C.-M. Oxidative dissolution of silver nanoparticles by dioxygen: A kinetic and mechanistic study. Chem. - Asian J. 2011, 6 (9), 2506-2511.
(17) Ho, C. M.; Yau, S. K.; Lok, C. N.; So, M. H.; Che, C. M. Oxidative dissolution of silver nanoparticles by biologically relevant oxidants: a kinetic and mechanistic study. Chem. - Asian J. 2010, 5 (2), 285-293.

(18) Yin, Y.; Yang, X.; Zhou, X.; Wang, W.; Yu, S.; Liu, J.; Jiang, G. Water chemistry controlled aggregation and photo-transformation of silver nanoparticles in environmental waters. J. Environ. Sci. 2015, 34, $116-125$.

(19) Yang, X.; Jiang, C.; Hsu-Kim, H.; Badireddy, A. R.; Dykstra, M.; Wiesner, M.; Hinton, D. E.; Meyer, J. N. Silver nanoparticle behavior, uptake, and toxicity in Caenorhabditis elegans: effects of natural organic matter. Environ. Sci. Technol. 2014, 48 (6), 3486-3495.

(20) Akaighe, N.; Maccuspie, R. I.; Navarro, D. A.; Aga, D. S.; Banerjee, S.; Sohn, M.; Sharma, V. K. Humic acid-induced silver nanoparticle formation under environmentally relevant conditions. Environ. Sci. Technol. 2011, 45 (9), 3895-3901.

(21) Hou, W. C.; Stuart, B.; Howes, R.; Zepp, R. G. Sunlight-driven reduction of silver ions by natural organic matter: formation and transformation of silver nanoparticles. Environ. Sci. Technol. 2013, 47 (14), 7713-7721.

(22) Yin, Y.; Liu, J.; Jiang, G. Sunlight-induced reduction of ionic Ag and $\mathrm{Au}$ to metallic nanoparticles by dissolved organic matter. ACS Nano 2012, 6 (9), 7910-7919.

(23) Fujii, M.; Rose, A. L.; Waite, T. D.; Omura, T. Oxygen and superoxide-mediated redox kinetics of iron complexed by humic substances in coastal seawater. Environ. Sci. Technol. 2010, 44, 93379342.

(24) Voelker, B. M.; Morel, F. M. M.; Sulzberger, B. Iron redox cycling in surface waters: Effects of humic substances and light. Environ. Sci. Technol. 1997, 31, 1004-1011.

(25) Jones, A. M.; Garg, S.; He, D.; Pham, A. N.; Waite, T. D. Superoxide-mediated formation and charging of silver nanoparticles. Environ. Sci. Technol. 2011, 45 (4), 1428-1434.

(26) Yu, S. J.; Yin, Y. G.; Chao, J. B.; Shen, M. H.; Liu, J. F. Highly dynamic PVP-coated silver nanoparticles in aquatic environments: chemical and morphology change induced by oxidation of $\mathrm{Ag}^{\mathrm{O}}$ and reduction of $\mathrm{Ag}^{+}$. Environ. Sci. Technol. 2014, 48 (1), 403-411.

(27) Furtado, L. M.; Norman, B. C.; Xenopoulos, M. A.; Frost, P. C.; Metcalfe, C. D.; Hintelmann, H. Environmental fate of silver nanoparticles in boreal lake ecosystems. Environ. Sci. Technol. 2015, 49 (14), 8441-8450.

(28) Wiesner, M. R.; Lowry, G. V.; Casman, E.; Bertsch, P. M.; Matson, C. W.; Di Giulio, R. T.; Liu, J.; Hochella, M. F., Jr Meditations on the ubiquity and mutability of nano-sized materials in the environment. ACS Nano 2011, 5 (11), 8466-8470.

(29) Buffle, J.; Wilkinson, K. J.; Stoll, S.; Filella, M.; Zhang, J. A generalized description of aquatic colloidal interactions: the threecolloidal component approach. Environ. Sci. Technol. 1998, 32 (19), 2887-2899.

(30) Lu, D.; Liu, Q.; Zhang, T.; Cai, Y.; Yin, Y.; Jiang, G. Stable silver isotope fractionation in the natural transformation process of silver nanoparticles. Nat. Nanotechnol. 2016, 11 (8), 682-686.

(31) Yang, L.; Dabek-Zlotorzynska, E.; Celo, V. High precision determination of silver isotope ratios in commercial products by MCICP-MS. J. Anal. At. Spectrom. 2009, 24 (11), 1564-1569.

(32) Luo, Y.; Dabek-Zlotorzynska, E.; Celo, V.; Muir, D. C.; Yang, L. Accurate and precise determination of silver isotope fractionation in environmental samples by multicollector-ICPMS. Anal. Chem. 2010, 82 (9), 3922-3928.

(33) Russell, W.; Papanastassiou, D.; Tombrello, T. Ca isotope fractionation on the Earth and other solar system materials. Geochim. Cosmochim. Acta 1978, 42 (8), 1075-1090.

(34) Linnik, P. N.; Ivanechko, Y. S.; Linnik, R. P.; Zhezherya, V. A. Humic substances in surface waters of the Ukraine. Russ. J. Gen. Chem. 2013, 83 (13), 2715-2730.

(35) Tejamaya, M.; Römer, I.; Merrifield, R. C.; Lead, J. R. Stability of citrate, PVP, and PEG coated silver nanoparticles in ecotoxicology media. Environ. Sci. Technol. 2012, 46 (13), 7011-7017. 
(36) Gunsolus, I. L.; Mousavi, M. P.; Hussein, K.; Buhlmann, P.; Haynes, C. L. Effects of humic and fulvic acids on silver nanoparticle stability, dissolution, and toxicity. Environ. Sci. Technol. 2015, 49 (13), 8078-8086.

(37) Akaighe, N.; Depner, S. W.; Banerjee, S.; Sharma, V. K.; Sohn, $M$. The effects of monovalent and divalent cations on the stability of silver nanoparticles formed from direct reduction of silver ions by Suwannee River humic acid/natural organic matter. Sci. Total Environ. 2012, 441, 277-89.

(38) Kittler, S.; Greulich, C.; Diendorf, J.; Koller, M.; Epple, M. Toxicity of silver nanoparticles increases during storage because of slow dissolution under release of silver ions. Chem. Mater. 2010, 22 (16), 4548-4554.

(39) Litvin, V. A.; Galagan, R. L.; Minaev, B. F. Kinetic and mechanism formation of silver nanoparticles coated by synthetic humic substances. Colloids Surf., A 2012, 414, 234-243.

(40) Huynh, K. A.; Chen, K. L. Aggregation kinetics of citrate and polyvinylpyrrolidone coated silver nanoparticles in monovalent and divalent electrolyte solutions. Environ. Sci. Technol. 2011, 45 (13), 5564-5571.

(41) Lau, B. L.; Hockaday, W. C.; Ikuma, K.; Furman, O.; Decho, A. $\mathrm{W}$. A preliminary assessment of the interactions between the capping agents of silver nanoparticles and environmental organics. Colloids Surf., A 2013, 435, 22-27.

(42) Hauri, E. H.; Carlson, R. W.; Bauer, J. The timing of core formation and volatile depletion in solar system objects from highprecision ${ }^{107} \mathrm{Pd}-{ }^{107} \mathrm{Ag}$ isotope systematics. Lunar Planet. Sci. Abs. 2000, 31, 1812.

(43) Gorham, J. M.; MacCuspie, R. I.; Klein, K. L.; Fairbrother, D. H.; Holbrook, R. D. UV-induced photochemical transformations of citrate-capped silver nanoparticle suspensions. J. Nanopart. Res. 2012, 14 (10), 1139.

(44) Grillet, N.; Manchon, D.; Cottancin, E.; Bertorelle, F.; Bonnet, C.; Broyer, M.; Lerme, J.; Pellarin, M. Photo-oxidation of individual silver nanoparticles: A real-time tracking of optical and morphological changes. J. Phys. Chem. C 2013, 117 (5), 2274-2282.

(45) Wiederhold, J. G. Metal stable isotope signatures as tracers in environmental geochemistry. Environ. Sci. Technol. 2015, 49 (5), 2606-2624.

(46) Kaegi, R.; Voegelin, A.; Sinnet, B.; Zuleeg, S.; Hagendorfer, H.; Burkhardt, M.; Siegrist, H. Behavior of metallic silver nanoparticles in a pilot wastewater treatment plant. Environ. Sci. Technol. 2011, 45 (9), 3902-3908.

(47) Impellitteri, C. A.; Harmon, S.; Silva, R. G.; Miller, B. W.; Scheckel, K. G.; Luxton, T. P.; Schupp, D.; Panguluri, S. Transformation of silver nanoparticles in fresh, aged, and incinerated biosolids. Water Res. 2013, 47 (12), 3878-3886.

(48) Kaegi, R.; Voegelin, A.; Ort, C.; Sinnet, B.; Thalmann, B.; Krismer, J.; Hagendorfer, H.; Elumelu, M.; Mueller, E. Fate and transformation of silver nanoparticles in urban wastewater systems. Water Res. 2013, 47 (12), 3866-3877.

(49) Kim, B.; Park, C.-S.; Murayama, M.; Hochella, M. F., Jr. Discovery and characterization of silver sulfide nanoparticles in final sewage sludge products. Environ. Sci. Technol. 2010, 44 (19), 75097514.

(50) Li, L.; Wang, Y.; Liu, Q.; Jiang, G. Rethinking stability of silver sulfide nanoparticles $\left(\mathrm{Ag}_{2} \mathrm{~S}-\mathrm{NPs}\right)$ in the aquatic environment: Photoinduced transformation of $\mathrm{Ag}_{2} \mathrm{~S}$-NPs in the presence of $\mathrm{Fe}(\mathrm{III})$. Environ. Sci. Technol. 2016, 50 (1), 188-196.

(51) Blaser, S. A.; Scheringer, M.; MacLeod, M.; Hungerbuhler, K. Estimation of cumulative aquatic exposure and risk due to silver: Contribution of nano-functionalized plastics and textiles. Sci. Total Environ. 2008, 390 (2-3), 396-409.

(52) Ivask, A.; Kurvet, I.; Kasemets, K.; Blinova, I.; Aruoja, V.; Suppi, S.; Vija, H.; Kakinen, A.; Titma, T.; Heinlaan, M.; Visnapuu, M.; Koller, D.; Kisand, V.; Kahru, A. Size-dependent toxicity of silver nanoparticles to bacteria, yeast, algae, crustaceans and mammalian cells in vitro. PLoS One 2014, 9 (7), e102108.
(53) Chen, K. Y.; Morris, J. C. Kinetics of oxidation of aqueous sulfide by oxygen. Environ. Sci. Technol. 1972, 6 (6), 529-537.

(54) Levard, C.; Mitra, S.; Yang, T.; Jew, A. D.; Badireddy, A. R.; Lowry, G. V.; Brown, G. E., Jr Effect of chloride on the dissolution rate of silver nanoparticles and toxicity to E. Coli. Environ. Sci. Technol. 2013, 47 (11), 5738-5745. 